\title{
REVIEW
}

\section{Clinical review: optimizing enteral nutrition for critically ill patients - a simple data-driven formula}

\author{
Refaat A Hegazi ${ }^{1}$ and Paul E Wischmeyer2*
}

\begin{abstract}
In modern critical care, the paradigm of 'therapeutic nutrition' is replacing traditional 'supportive nutrition.' Standard enteral formulas meet basic macro- and micronutrient needs; therapeutic enteral formulas meet these basic needs and also contain specific pharmaconutrients that may attenuate hyperinflammatory responses, enhance the immune responses to infection, or improve gastrointestinal tolerance. Choosing the right enteral feeding formula may positively affect a patient's outcome; targeted use of therapeutic formulas can reduce the incidence of infectious complications, shorten lengths of stay in the ICU and in the hospital, and lower risk for mortality. In this paper, we review principles of how to feed (enteral, parenteral, or both) and when to feed (early versus delayed start) patients who are critically ill. We discuss what to feed these patients in the context of specific pharmaconutrients in specialized feeding formulations, that is, arginine, glutamine, antioxidants, certain $\omega-3$ and $\omega-6$ fatty acids, hydrolyzed proteins, and mediumchain triglycerides. We summarize current expert guidelines for nutrition in patients with critical illness, and we present specific clinical evidence on the use of enteral formulas supplemented with anti-inflammatory or immune-modulating nutrients, and gastrointestinal tolerance-promoting nutritional formulas. Finally, we introduce an algorithm to help bedside clinicians make data-driven feeding decisions for patients with critical illness.
\end{abstract}

\section{From supportive nutrition to therapeutic nutrition} In patients who are critically ill, there is no doubt that nutritional status and clinical outcome are linked [1].

*Correspondence: Paul.Wischmeyer@ucdenver.edu

2Department of Anesthesiology, University of Colorado School of Medicine, 12700 E. 19th Ave, Box 8602, RC2 P15-7120, Aurora, CO 80045, USA

Full list of author information is available at the end of the article
ICU patients typically experience catabolic stress and systemic inflammatory response; in turn, these responses alter both the morphology and function of the gastrointestinal (GI) tract [2]. Up to $60 \%$ of ICU patients suffer GI dysfunction due to impaired GI motility, digestion, or absorption [3,4]. Such GI dysfunction, often coupled with inadequate caloric intake, leads many critically ill patients to develop an energy deficit and lose lean body mass [5-10].

ICU patients with poor nutritional status commonly experience immune dysfunction, weakened respiratory muscles and lowered ventilation capacity, and reduced GI tolerance $[11,12]$. As a result, patients are at risk for a wide range of complications: ventilator dependence; GI dysfunction with gastroesophageal reflux, esophagitis, or pulmonary aspiration; and infections that can lead to sepsis, multi-organ failure, and even death $[1,12,13]$. For such patients, supportive nutrition has long been used as adjunctive care; however, such nutrition is often inadequate, including only fundamental macronutrients to sustain patients through periods of metabolic stress.

Feeding an ICU patient now extends beyond choosing the right feeding route, the rate, and the caloric density. In modern critical care, the paradigm of 'therapeutic nutrition' is replacing traditional 'supportive nutrition' [14]. Enteral feeds are now formulated with active nutrients that may help reduce oxidative damage to cells and tissues, modulate inflammation, enhance beneficial stress responses, and improve feeding tolerance.

In this review, we summarize the most recent data on feeding critically ill patients. We describe practice guidelines established by US, European and Canadian enteral and parenteral nutrition societies, beginning with recommendations of how to feed (enteral, parenteral, or both) and when to feed (early versus delayed start). We systematically discuss what to feed critically ill patients by reviewing mechanisms of action for specific pharmaconutrients and by concisely summarizing current guidelines and expert recommendations for feeding various populations in the ICU. We compile clinical evidence on feeding anti-inflammatory, immune-modulating, and GI tolerance-promoting nutritional formulas in specific patient subgroups. Finally, we introduce a straightforward 
algorithm to help bedside clinicians make feeding decisions for patients with critical illness.

\section{The basics: how and when to initiate feeding in ICU patients}

Many ICU patients are incapable or intolerant of a food diet; therefore, a clinician's first nutritional decision is whether to tube-feed enterally, parenterally, or with a combination of both.

Practice guidelines in Europe, Canada, and the US endorse enteral feeding for patients who are critically ill and hemodynamically stable $[1,11,15]$. Enteral nutrition is preferred over parenteral nutrition (PN) for most ICU patients - an evidence-based practice supported by numerous clinical trials involving a variety of critically ill patient populations, including those with trauma, burns, head injury, major surgery, and acute pancreatitis $[1,16]$. For ICU patients who are hemodynamically stable and have a functioning GI tract, early enteral feeding (within 24 to 48 hours of arrival in the ICU) has become a recommended standard of care $[1,11,15]$. Experts identify these early hours as a window of opportunity to provide nutrition that maintains gut barrier function and supports immune responses $[1,11]$.

Patients with extreme hemodynamic instability - with rising plasma/blood/serum lactate concentrations or escalating requirements for vasopressors - are generally not considered candidates for enteral feeding. However, early findings suggest use of early enteral feeding in other vasopressor-dependent patients. In one study, vasopressordependent patients who were given enteral feeding within the first 48 hours had a significant survival advantage compared to those whose feeding was delayed; in fact, the sickest patients (on multiple vasopressors) experienced the greatest benefit [17]. It should be noted that this finding is based on an observational study. A confirmatory prospective, controlled study is warranted.

Even though early enteral nutrition is favored for most ICU patients, caloric and protein needs are often not met by enteral feeding [10]. Nutritional intake may be hampered by setting target levels too low, interruption of feeding for procedures, issues of airway management, and poor tolerance of feedings $[8,18,19]$. To enhance use of enteral feeding in ICU patients, several feeding strategies have been proposed recently: shift from an hourly-rate feeding goal to a 24-hour volume goal, allowing nurses to 'make-up' for interruptions and meet feeding targets [20]; accept gastric residual volumes up to $500 \mathrm{~mL}$ to increase the volume of formula delivered in practice [1,20-22]; and use a promotility agent to help reduce gastric residual volume $[20,21,23]$.

$\mathrm{PN}$ is necessary in critically ill patients who do not have an intact GI tract, but current guidelines do not agree on when to initiate PN [5]. For patients who are intolerant or have other contraindications to enteral feeding, European guidelines recommend starting PN within 24 to 48 hours if the patient is not expected to be on oral nutrition within 3 days [24]. US guidelines hesitate to recommend PN on admission to the ICU; standard care (intravenous fluids) is recommended first, with PN reserved and initiated only after 7 days in well-nourished patients [1]. Both the European Society for Parenteral and Enteral Nutrition (ESPEN) and American Society for Parenteral and Enteral Nutrition (ASPEN) guidelines recommend early PN use (within 24 hours of ICU admission) in patients who are malnourished $[1,24]$. Canadian guidelines state that PN should not be used in any patient with an intact GI tract [25].

When enteral feeding alone is inadequate, some experts are calling for use of PN and enteral nutrition together to meet energy and protein targets $[5,7,26,27]$. Combination regimens are justified by observations that actual enteral intake typically meets only half of prescribed calories in ICU patients [6,8-10]. For patients who are expected to be mechanically ventilated for more than 72 hours and have body mass index (BMI) scores $<25$ or $\geq 35$, each additional $1,000 \mathrm{kcal} /$ day or $30 \mathrm{~g}$ protein/day was reported to be associated with reduced mortality [27].

However, clinical evidence for combination feeding remains unclear. Two recent randomized trials have helped clarify this subject. Casaer and colleagues [28] conducted a large, single center prospective, randomized trial (EPaNIC trial) comparing outcomes in critically ill patients on enteral nutrition who had early versus late initiation of PN (early, $<48$ hours after ICU admission, $\mathrm{n}=2,312$; late, day 8 or later after ICU admission, $\mathrm{n}=2,328)$. Results revealed patients on late-initiation PN had a relative increase of $6 \%$ in the likelihood of being discharged alive earlier from the ICU and from the hospital $(P=0.04)$. Those in the late-initiation group also had significantly fewer ICU infections, shorter duration of mechanical ventilation and a shorter course of renal replacement therapy. Several aspects of the study limit generalizability of the findings to all ICU populations. First, patients with chronic malnutrition were not included in the study. Second, the trial PN formulation did not contain either glutamine or immune-modulating ingredients, nor was there any adjustment for presence/ absence of immune-modulating ingredients in enteral feedings. Third, patients in the trial received a low protein delivery (median of $0.8 \mathrm{~g} / \mathrm{kg} /$ day protein (after day 3)) for the study period in the early PN group; this protein target is below what is recommended by most guidelines for critically ill patients (the typical recommendation is 1.3 to $1.5 \mathrm{~g} / \mathrm{kg} /$ day (ESPEN guidelines)). Finally, the trial examined a low mortality-risk patient group with an average ICU mortality of $6.2 \%$ (90-day mortality of $11.2 \%$ ) and a relatively low severity patient group with an 
ICU length of stay of 3.5 days, and a mechanical ventilation period of 2 days. Accounting for the aforementioned limitations, The EPaNIC trial is unquestionably a key contribution to the literature on supplemental PN use in critical care. We believe the key conclusion is that early aggressive calorie delivery via PN does not appear to be beneficial in low mortality risk, non-chronically malnourished patients. In contrast, the recently published, single center TICACOS trial showed hospital and 60 -day mortality was reduced $(P<0.02$ for both time points) in a higher mortality risk group of ICU patients receiving additional calories via enteral nutrition supplemented with PN [29]. In comparison to the EPaNIC trial, the TICACOS trial was conducted in a higher risk ICU patient group with an ICU mortality of $25.4 \%$ (60-day mortality of $47 \%$ ), ICU length of stay of 12 days, and a mechanical ventilation period of 10.75 days. Thus, it is possible that supplemental PN may improve outcome in high mortality risk ICU patients. Additional trials on the use of enteral nutrition with supplemental PN have recently been completed or are underway. These forthcoming results should continue to clarify the utility of supplemental PN use in the ICU.

\section{Choosing which enteral formulation to feed}

For most ICU patients, the next decision is what enteral formula to feed. Critically ill patients are a heterogeneous population, so no one-size-fits-all nutritional formula should be expected [30,31]. Feeding formulas to consider are anti-inflammatory, immune-modulating, GI tolerancepromoting, and standard enteral nutrition.

\section{What are the key functional pharmaconutrients in enteral formulas?}

Guidelines from professional nutrition societies around the world identify certain populations of patients who can benefit from formulations with specific pharmaconutrients $[1,11,15,25]$. For many others, each physician must use his or her own clinical judgment about what formula will best meet the patient's needs. To help guide such choices, the following section reviews functional pharmaconutrients and their roles in critically ill patients.

\section{Anti-inflammatory enteral nutrients}

Critical illness and injury are characterized by oxidative stress and excessive inflammation, harmful processes that damage cells and impair function of vital organs. Extreme inflammation - as in patients with systemic inflammatory response syndrome (SIRS), sepsis, acute lung injury (ALI), or acute respiratory distress syndrome (ARDS) - often progresses to multiple organ dysfunction syndrome and even death. Feeding formulas with specific pharmaconutrients can help offset tissue damage and moderate inflammation. Dietary antioxidants (vitamins
$\mathrm{A}, \mathrm{C}$, and $\mathrm{E}$ and selenium) play important roles in reducing potential for tissue damage by stabilizing free radicals in cells, while dietary fish oil and borage oil blunt out-ofcontrol inflammatory responses by modulating synthesis of pro- and anti-inflammatory mediators [31-33].

\section{Fish oil and borage oil}

Dietary intake of certain oils alters the fatty acid composition in membranes of cells involved in immune inflammatory responses, that is, neutrophils and macrophages. Certain cell membrane fatty acids (for example, arachidonic acid (AA)) serve as precursors to inflammatory eicosinoids and leukotriene mediators, while other fatty acids (eicosapentaenoic acid (EPA), docosohexaenoic acid (DHA), gamma linolenic acid (GLA)) are metabolized to form less pro-inflammatory mediators [31-34]. In addition, DHA and EPA are precursors of resolvins and protectins, which help resolve inflammation and reduce tissue injury [35].

Fish oils are rich in the $\omega-3$ fatty acids EPA and DHA, the active metabolites of alpha-linolenic acid [31-33]. While healthy humans have desaturase enzymes that convert alpha-linolenic acid to EPA and DHA, such conversion is negligible in individuals who are critically ill. As a result, enteral nutrition containing EPA and DHA can help quell excessive inflammatory responses. The anti-inflammatory actions of the $\omega-3$ fatty acids EPA and DHA are thought to occur by (1) blunting production of pro-inflammatory mediators as a result of replacing AA in macrophage and neutrophil membranes, (2) blocking synthesis of pro-inflammatory mediators from AA by competing for the metabolic enzymes cyclooxygenase and lipoxygenase, and (3) supporting production of less inflammatory prostaglandin and leukotriene mediators [34] (Figure 1). Oil from the borage plant contains GLA, an $\omega-6$ fatty acid that similarly competes with proinflammatory AA for conversion enzymes; GLA is a precursor to mediators that are less inflammatory than the prostaglandins and leukotrienes produced from AA [31].

Results vary in studies using fish oil-supplemented enteral formulas in critically ill patients, partly because of the different formulations and doses of fish oil. However, an enteral formula containing EPA and GLA consistently showed significant benefits in three studies of mechanically ventilated patients with ALI/ARDS or severe sepsis/septic shock [36-38] (Figure 2). Use of this antiinflammatory feeding formulation significantly reduced time on ventilator, ICU and hospital lengths of stay, and incidence of new organ failure. Further, a meta-analysis performed by the authors of the original trials showed that the use of a fish-oil-containing formula significantly reduced the risk of 28 -day mortality by $49 \%$ compared to a high fat control enteral formulation [39]. Results of another large meta-analysis showed that immune-modulating 


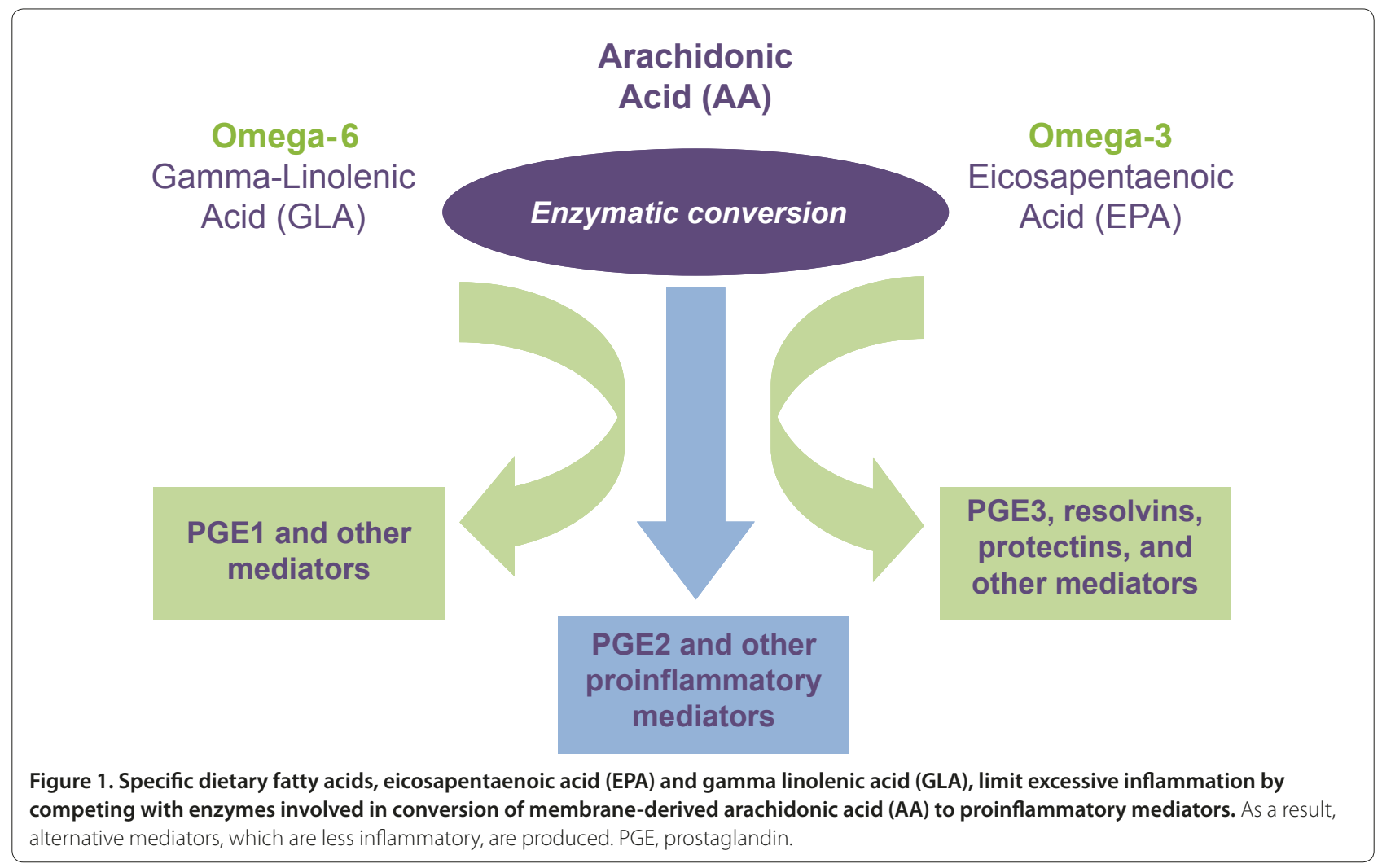

formulas containing fish oil significantly reduced by half the risk for mortality and secondary infections and significantly shortened length of hospital stay by more than 6 days in ICU patients with ALI/ARDS or severe sepsis/septic shock; such significant benefits were not seen in trauma and burn patients [40]. Moreover, a recent study of critically ill mechanically ventilated, septic patients (not all of whom had ARDS) found that feeding a formula enriched with EPA, GLA, and antioxidants shortened ICU stay but did not show benefits in terms of infectious complications, gas exchange, or organ failures [41].

\section{Antioxidant nutrients}

Antioxidant enzymes (superoxide dismutase, catalase, and glutathione peroxidase) - in association with selenium, zinc, manganese, and iron - provide intrinsic defense mechanisms to remove reactive oxygen species generated by everyday living [33]. However, critical illness or injury leads to increased oxidative stress, and these enzymes and their cofactors can be depleted.

In critical illness, patients with a history of deficient dietary intake of antioxidant vitamins were more likely to suffer redox imbalance than were those whose antioxidant vitamin intake was near the recommended daily allowance [42]. Repletion studies showed that survival was improved when such patients were given supplemental antioxidant vitamins and minerals and trace elements (for example, vitamins $\mathrm{A}, \mathrm{C}$ and $\mathrm{E}$, selenium, copper, and zinc) [25,43]. A multi-center study showed reduced mortality rates when patients were given high-dose selenium by intravenous supplementation [44]. There were two limitations to this multi-center study: specifically, the reduction in mortality with selenium was only apparent when data were analyzed as per-protocol, and the number of exclusions was substantial.

\section{Immune-modulating enteral nutrients}

Arginine, glutamine and nucleotides are conditionally essential nutrients that can be depleted by stresses of critical illness and injury. These nutrients usually support immune homeostasis by maintaining the functional integrity of immune cells and helping in wound healing and tissue repair processes. With nutritional deficits, the function of the immune system is impaired. For instance, arginine deficiency develops in patients who have experienced surgery or trauma [45]. Glutamine deficiency occurs in many ICU patients, including those with sepsis, trauma, surgery, or burns $[31,33,46,47]$. Similarly, during times of stress and rapid cell proliferation, nucleotide availability may be rate-limiting for synthesis of nucleotide-derived compounds. In the next sections, we review pivotal roles of these three nutrients in modulating immune responses. 


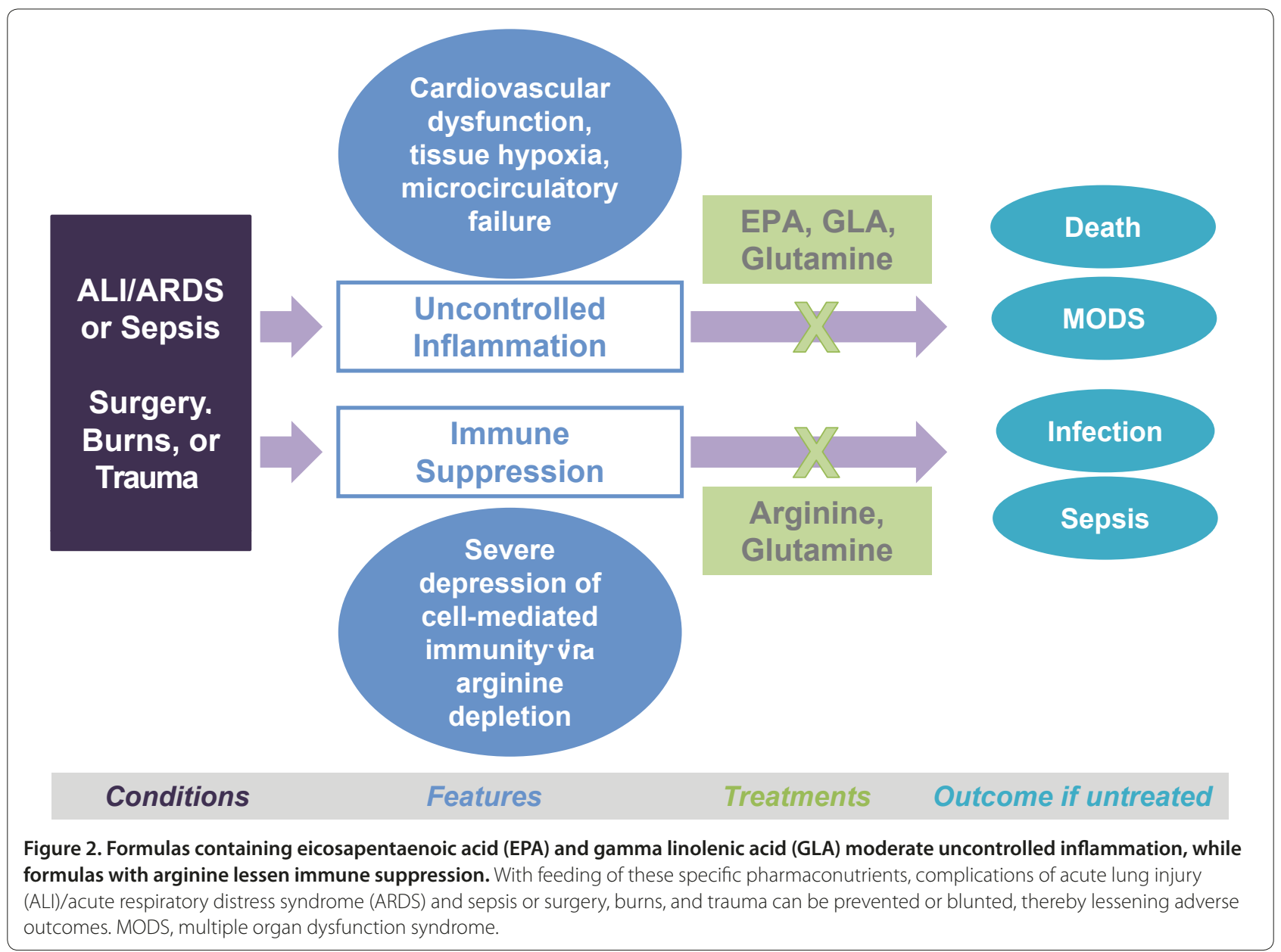

\section{Arginine}

Arginine is a conditionally essential amino acid that is supplied by the diet, synthesized endogenously, and salvaged from body proteins [45]. It supports polyamine synthesis (for cell growth and proliferation), proline synthesis (for wound healing), and is a biosynthetic substrate for nitric oxide (a signaling molecule for immune and other cells) $[31,33,45]$.

Results of recent investigations revealed how immune function is tied closely to arginine metabolism [49]. Soon after injury or surgery, immature cells of myeloid origin appear in the circulation and in lymph tissues. These cells produce arginase-1, an enzyme that breaks down arginine. Increased arginine breakdown, coupled with low intake and limited endogenous production, results in overall arginine deficiency. This deficiency is associated with suppression of T-lymphocyte function. T-lymphocyte dysfunction after surgery or trauma is characterized by a decrease in the number of circulating CD4 cells, blunted T-cell proliferation, decreased production of IL-2 and interferon gamma, and loss of the zeta $(\zeta)$ chain, a peptide essential in the T-cell receptor complex [48].
Results of several clinical studies showed that repletion of arginine, along with $\omega-3$ fatty acids, helps restore Tlymphocyte numbers and function - that is, CD4 cell counts and IL-2 production $[48,49]$. Dietary $\omega-3$ fatty acids also blunt expression of arginase 1 [50]. Thus, substantial evidence supports the concept that immunemodulating diets exert their beneficial effects by restoring T-cell function that was impaired by arginine depletion.

Clinical outcome data (30 trials; 3,000 patients) showed a significant treatment effect of arginine supplementation following major surgery; arginine treatment reduced the risk of infection (relative risk $=0.58 ; 95 \%$ confidence interval (CI) of 0.48 to $0.69 ; P<0.00001$ ) and overall length of stay (weighted mean difference $=-2.09$; $95 \% \mathrm{CI}$ of -3.20 to $-0.97 ; P=0.0002$ ) versus standard enteral nutrition [51]. In addition, arginine (at doses given in immune-modulating nutrition, 12 to $15 \mathrm{~g}$ /day) is potentially helpful for patients for 5 to 7 days prior to major surgery (as studied in abdominal, ear/nose/throat, and cardiac surgery) $[45,51]$. However, very little benefit, and perhaps harm, is observed in patients with severe sepsis $[52,53]$. This potential harm may be caused by promotion 
of excessive nitric oxide production in patients with sepsis, in turn worsening SIRS and increasing risk for mortality [54]. Nevertheless, these mechanisms are considered expert opinions rather than proven effects. For instance, lesser doses of arginine (6 $\mathrm{g}$ intravenously or orally) appear to have undetectable effects on blood pressure in healthy subjects [55].

Taken together, clinical evidence supports the concept that arginine-containing formulas should be considered as a standard of care in the peri-operative period, that is, both before and after major surgery (Figure 2). Trauma and post-myocardial infarction patients, and those with pulmonary hypertension may also benefit from supplemental arginine following injury [45]. For patients with severe sepsis, arginine-supplemented enteral formulas should be used with extreme caution [1] or avoided due to potential harm $[15,25,40,54]$.

\section{Glutamine}

Glutamine is the most abundant free amino acid in the body, but its stores are rapidly depleted during critical illness or injury, including burns $[31,46,56]$. Glutamine serves as a metabolic substrate for enterocytes and immune cells, thus supporting intestinal barrier function and immune responses [56]. Glutamine was recently proposed to serve as a signaling molecule in states of illness and injury, that is, a messenger to turn on genes involved in cell protection and immune regulation [57].

Glutamine is expected to have the greatest benefit in severely ill patients with sepsis and organ failure, that is, those with the most severe glutamine deficiency. Further, glutamine deficiency at ICU admission has been correlated with increased mortality [58]. Clinical evidence for glutamine-supplemented parental nutrition comes from randomized controlled trials (900 patients; 4 level 1 and 13 level 2 randomized controlled trials); together these studies show significant reductions in mortality, infection, and hospital length of stay [25]. Glutamine use is supported by clinical nutrition guidelines worldwide $[1,11,15,25]$.

Enteral formulations with glutamine appear to benefit patients with burns or trauma [25]. Benefits are dosedependent, with $>0.3 \mathrm{~g} / \mathrm{kg} /$ day required for benefit; $0.5 \mathrm{~g} / \mathrm{kg} /$ day (in divided portions) may be more effective [25]. A meta-analysis of all glutamine randomized controlled trials (both enteral and parenteral) showed a statistically significant reduction in mortality in ICU patients of all types (21 studies, more than 1,500 patients) [25]. More data are needed to support the routine use of enteral glutamine in other critically ill patients.

\section{Nucleotides}

Nucleotides play an active role in cell proliferation and immune modulation. They are low molecular weight, intracellular compounds that serve as building blocks for DNA, RNA, and ATP, and are components of several key metabolic coenzymes [33]. Nucleotides can be synthesized de novo, or they can be retrieved through salvage pathways. During times of stress and rapid cell proliferation, nucleotide availability may be rate-limiting for synthesis of nucleotide-derived compounds. Dietary supplies help compensate for these shortfalls, in turn supporting cell proliferation, differentiation, and function, especially for cells of the immune system [33]. Evidence for benefits of dietary nucleotides comes from preclinical studies, so clinical outcome trials are still needed. While nucleotides are unlikely to cause harm, their inclusion in therapeutic nutrition cannot yet be recommended.

\section{Tolerance-promoting prebiotic formulas}

Enteral-feeding intolerance is common in critically ill patients [59]. Such intolerance is attributed to illnessassociated intestinal dysfunction, such as impaired motility, inadequate digestion, and reduced absorption, as well as to side effects of treatment drugs. Half of all ICU patients on enteral nutrition have some symptoms of intolerance, that is, increased residual volume, bowel dilation, vomiting, or diarrhea [3,4]. About $80 \%$ of patients with head injury and $50 \%$ of mechanically ventilated and post-surgical patients have delayed gastric emptying [60-62].

Certain diseases and conditions predispose patients to GI problems. Not surprisingly, abdominal surgery contributes to GI tract dysfunction, including laparoscopic procedures where the gut is not handled at all [63]. Patients with burns and traumatic injuries may experience GI motility problems [63,64]. In sepsis, exocrine pancreatic function is reduced, which can impair protein digestion [65]. Treatments for cancer and other conditions - for example, opiates, radiotherapy, or chemotherapy - have side effects of anorexia and impaired GI function [66].

In such situations, tolerance-promoting enteral formulas are a rational feeding choice. Enteral formulas with extensively hydrolyzed proteins, that is, peptide-based feeding formulas, can be fed to patients intolerant of whole proteins. Enterocytes normally absorb small peptides (primarily di- and tripeptides), so proteins do not need to be fully digested to single amino acids for uptake [67]. It will be important to confirm that this mechanism for peptide uptake remains active in critically ill patients.

Further, tolerance-promoting formulas often supply fats as medium-chain triglycerides, that is, lipids that are small enough to be water-soluble with little or no bile salt. Compared to long-chain fats, the medium-chain triglycerides appear to be tolerated because they are quickly absorbed by the intestine and metabolized by the liver. The length of a fatty acid chain may influence 
Table 1. Summary of expert recommendations on harm/benefit of specific ingredients in feeding formulas by population of critically ill patients $[1,15,25]$

\begin{tabular}{|c|c|c|c|}
\hline Patients & CCCPG & ESPEN & ASPEN/SCCM \\
\hline \multirow[t]{3}{*}{ General } & Arginine (no benefit) & No recommendation & Arginine (possible benefit) \\
\hline & No recommendation & No recommendation & Glutamine (possible benefit) \\
\hline & Antioxidants (possible benefit) & No recommendation & Antioxidants (benefit) \\
\hline Elective surgery & No recommendation & Arginine (benefit) & Arginine (benefit) \\
\hline \multirow[t]{3}{*}{ Trauma } & Arginine (no benefit) & Arginine (benefit) & Arginine (benefit) \\
\hline & Glutamine (possible benefit) & Glutamine (benefit) & Glutamine (possible benefit) \\
\hline & No recommendation & No recommendation & Antioxidants (benefit) \\
\hline \multirow[t]{3}{*}{ Burns } & Arginine (no benefit) & No recommendation & Arginine (benefit) \\
\hline & Glutamine (possible benefit) & Glutamine (benefit) & Glutamine (possible benefit) \\
\hline & No recommendation & Antioxidants (benefit) & Antioxidants (benefit) \\
\hline \multirow[t]{2}{*}{ Sepsis } & Arginine (harm) & $\begin{array}{l}\text { Arginine (harm if severe sepsis; } \\
\text { benefit if mild) }\end{array}$ & $\begin{array}{l}\text { Arginine (harm if severe sepsis; } \\
\text { benefit if mild/moderate) }\end{array}$ \\
\hline & No recommendation & No recommendation & Antioxidants (benefit) \\
\hline \multirow[t]{3}{*}{ ALI/ARDS } & $\begin{array}{l}\omega-3 \text { fatty acids and } \omega-6 \text { gamma-linolenic } \\
\text { acid (benefit) }\end{array}$ & $\omega-3$ fatty acids (benefit) & $\begin{array}{l}\omega-3 \text { fatty acids and } \omega-6 \text { gamma-linolenic } \\
\text { acid (benefit) }\end{array}$ \\
\hline & Arginine (no benefit) & No recommendation & No recommendation \\
\hline & No recommendation & Antioxidants (benefit) & Antioxidants (benefit) \\
\hline $\begin{array}{l}\text { Enteral feeding } \\
\text { intolerance }\end{array}$ & $\begin{array}{l}\text { Whole-protein formulas for most patients; } \\
\text { hydrolyzed protein formula may be } \\
\text { considered for patients with Gl } \\
\text { dysfunction such as short bowel } \\
\text { syndrome, pancreatitis }\end{array}$ & $\begin{array}{l}\text { Whole-protein formulas for most } \\
\text { patients; hydrolyzed protein formula } \\
\text { may be considered for Gl dysfunction } \\
\text { such as pancreatitis }\end{array}$ & $\begin{array}{l}\text { Hydrolyzed protein formula may be considered } \\
\text { for patients with Gl dysfunction such as } \\
\text { persistent diarrhea, pancreatitis }\end{array}$ \\
\hline
\end{tabular}

ASPEN, American Society for Parenteral and Enteral Nutrition; CCCPG, Canadian Critical Care Practice Guidelines; ESPEN, European Society for Clinical Nutrition and Metabolism; Gl, gastrointestinal; SCCM, Society of Critical Care Medicine.

gastric emptying, at least in part, via a reduction in GI hormones such as cholecystokinin and glucagon-like peptide-1 [68].

Prebiotic ingredients also help improve GI tolerance of enteral formulations; prebiotics are non-digestible food ingredients, mainly carbohydrates, that stimulate growth of beneficial bacteria in the digestive system, in turn benefiting the health of the host $[69,70]$. In one study of patients with acute pancreatitis, feeding an enteral formula with prebiotics (a mix of fructooligosaccharides and other soluble and insoluble fibers) significantly improved clinical outcomes and lessened disease severity compared to feeding a fiber-free formula [71]. More studies are warranted and needed to determine the clinical effects of prebiotic-supplemented enteral formulations in critically ill patients [72].

Expert guidelines for therapeutic enteral nutrition in the ICU Evidence-based nutrition guidelines for critically ill patients have been developed in North America and Europe $[1,15,25]$. While the guidelines agree in principle regarding pharmaconutrients, there are some differences in specific recommendations (Table 1 ).

\section{Enteral formulas with anti-inflammatory nutrients}

Enteral formulas supplemented with inflammationmoderating fats ( $\omega-3$ fish oils DHA and EPA, and $\omega-6$ borage oil GLA) and antioxidants are recognized in evidence-based guidelines to blunt inflammatory responses and protect against free radical damage $[1,15,25]$. All guidelines specifically recommend the use of $\omega-3$ fatty acids in ALI/ARDS patients $[1,15,25]$, and all guidelines support enrichment of antioxidant vitamins and trace elements in enteral formulas $[1,15,25]$.

\section{Enteral formulas with immune-modulating nutrients}

Formulas with immune-modulating nutrients, such as arginine, glutamine, and possibly nucleotides, support immune responses and lower risks of infectious complications in many patients. While some recommendations group these nutrients together, recent findings identify specific indications for each nutrient. 


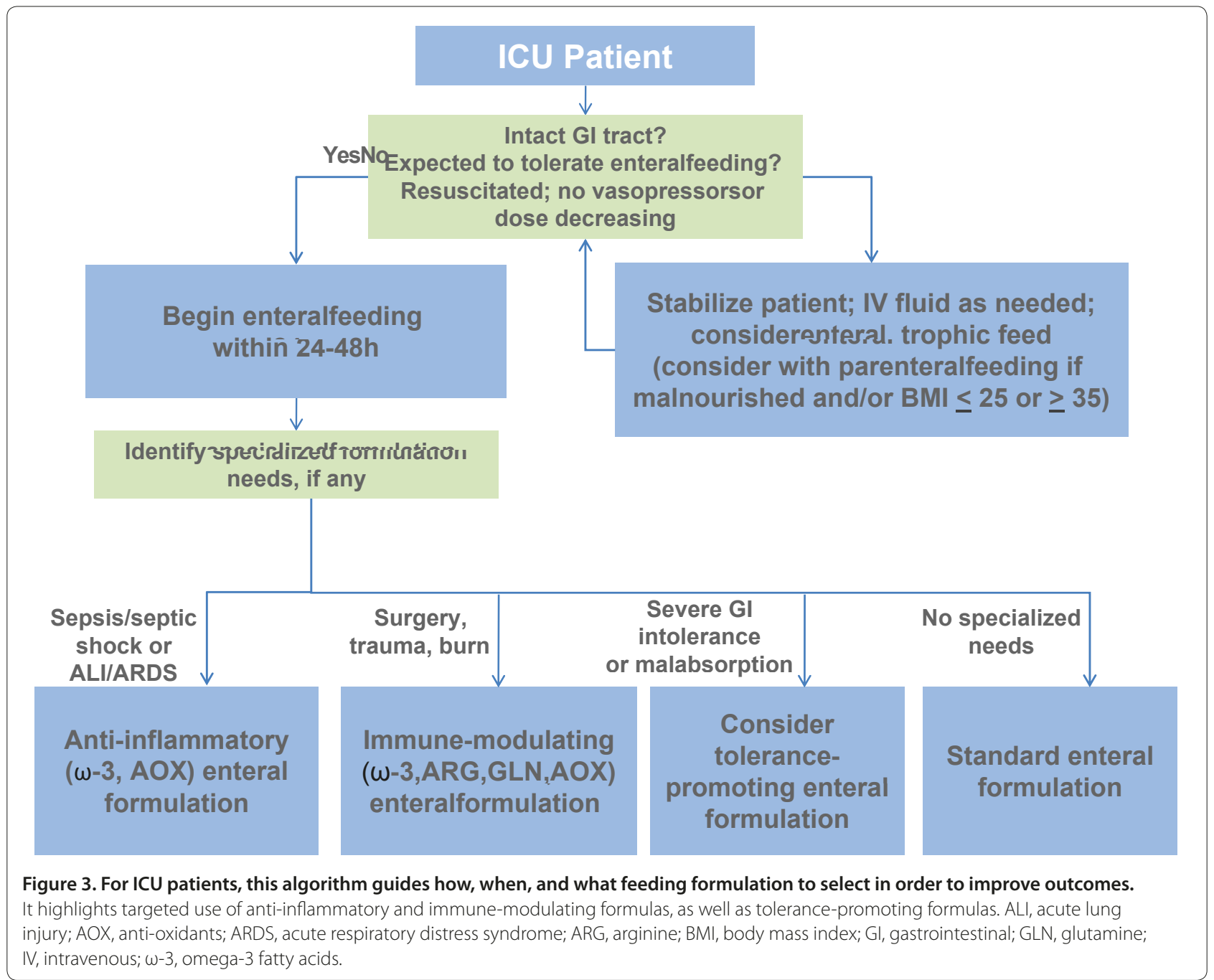

Enteral formulations with arginine are recommended for surgical patients $[1,15]$. By contrast, guidelines advise using arginine with caution in patients who are experiencing inflammatory responses following infection, such as those with severe sepsis or septic shock, due to arginine's potential for increasing endogenous production of nitric oxide [1,15,25].

Glutamine-supplemented enteral nutrition is specifically recommended for burn and trauma patients; glutamine is recommended for all patents on $\mathrm{PN}[1,15,25]$.

Nucleotides may be conditionally essential for cell proliferation during times of metabolic stress, but only European and US guidelines mention theoretical benefits from nucleotide supplementation in immune-modulating formulas $[1,15]$. Canadian guidelines do not support this practice [25].

Enteral formulas designed to promote gastrointestinal tolerance Peptide- and medium-chain triglyceride-based formulas with prebiotics lessen GI tolerance problems related to enteral nutrition. Guidelines specifically recommend hydrolyzed protein formulas for patients with GI dysfunction, such as short bowel syndrome, pancreatitis, or persistent diarrhea $[1,15,25]$. Guidelines have not yet made recommendations regarding fiber content for enteral feeding in the ICU.

\section{Choosing the right feeding formula for an ICU patient}

When considering nutritional therapy for ICU patients, three main decisions must be made on the basis of the patient's medical condition, as indicated in the algorithm provided (Figure 3): (1) route of feeding - enteral versus parenteral; (2) when to feed - begin within 24 to 48 hours of ICU admission preferred (early enteral feeding); and (3) what to feed - a standared enteral formula or one with targeted functional ingredients (anti-inflammatory, immune-modulating, or tolerance-promoting nutrients).

This nutrition algorithm is intended as a guide for choosing the right therapeutic nutrition formula; as 
always, clinical judgment also plays a very important role in decision-making. In choosing, clinicians may need to consider other factors, such as whether formula cost is a limiting factor and what to choose when conditions coincide - for example, sepsis and GI intolerance. In addition, the health and nutritional status of a patient can change rapidly - for example, a trauma patient develops sepsis. As a result, the nutritional needs of a critically ill patient should be reassessed routinely and often.

\section{Conclusions}

Nutrition - given early and by the enteral route - is now well established in the ICU. We believe future ICU nutrition algorithms need to focus on evidence-based therapeutic nutrition as a new standard of care. In our opinion, the modern ICU clinician now has the opportunity to make full use of specialized nutrition in the ICU, that is, formulas supplemented with anti-inflammatory, immune-modulating, and tolerance-promoting nutrients. Each formula type contains a combination of pharmaconutrients that have the potential to enhance natural recovery processes, prevent or blunt certain disease-related complications, and provide vital energy as well-tolerated macronutrients. Antioxidant vitamins and minerals, arginine, glutamine, certain $\omega-3$ long-chain fatty acids, hydrolyzed proteins, and medium-chain triglycerides are functional nutrients. By providing full macro- and micronutrient support along with these pharmaconutrients, therapeutic nutrition offers fresh hope for improved outcomes in ICU patients.

\section{Abbreviations}

$A A$, arachidonic acid; $A L I$, acute lung injury; $A R D S$, acute respiratory distress syndrome; ASPEN, American Society for Parenteral and Enteral Nutrition; $\mathrm{Cl}$, confidence interval; DHA, docosohexaenoic acid; EPA, eicosapentaenoic acid; ESPEN, European Society for Parenteral and Enteral Nutrition; GI, gastrointestinal; GLA, gamma linolenic acid; PN, parenteral nutrition; SIRS, systemic inflammatory response syndrome.

\section{Competing interests}

$\mathrm{RH}$ works for Abbott Nutrition. The material presented in this article is based on the best-known clinical evidence and is not affected by this financial relationship. PW receives research funding for nutrition work in critical illness from the National Institutes of Health (R01 GM078312, U01 DK069322), US Department of Defense, American Burn Association, and Fresenius Inc. He has also served as an occasional consultant and/or speaker for Abbott, Baxter Fresenius, and Nestle.

\section{Authors' contributions}

$\mathrm{RH}$ and $\mathrm{PW}$ have made substantial contributions to interpretation of the reviewed information; have been involved in drafting the manuscript and in revising it critically for important intellectual content; and have given final approval of the version to be published.

\section{Acknowledgements}

We thank Dr Cecilia Hofmann, medical writer, for her assistance in preparing the final version of the manuscript. She provided library and bibliography management support, edited the draft prepared by the authors, and formatted the manuscript for publication. She provided these services on behalf of Abbott Nutrition.

\section{Author details}

'Adult Nutrition Research and Development, Abbott Nutrition, 3300 Stelzer Rd, Columbus, OH 43219, USA. ${ }^{2}$ Department of Anesthesiology, University of Colorado School of Medicine, 12700 E. 19th Ave, Box 8602, RC2 P15-7120, Aurora, CO 80045, USA

Published: 30 November 2011

\section{References}

1. McClave SA, Martindale RG, Vanek WW, McCarthy M, Roberts P, Taylor B, Ochoa JB, Napolitano L, Cresci G: Guidelines for the Provision and Assessment of Nutrition Support Therapy in the Adult Critically III Patient: Society of Critical Care Medicine (SCCM) and American Society for Parenteral and Enteral Nutrition (A.S.P.E.N.). JPEN J Parenter Enteral Nutr 2009, 33:277-316.

2. Peuhkuri $K$, Vapaatalo H, Korpela R: Even low-grade inflammation impacts on small intestinal function. World J Gastroenterol 2010, 16:1057-1062.

3. Mentec H, Dupont H, Bocchetti M, Cani P, Ponche F, Bleichner G: Upper digestive intolerance during enteral nutrition in critically ill patients: frequency, risk factors, and complications. Crit Care Med 2001, 29:1955-1961.

4. Reintam A, Parm P, Kitus R, Kern H, Starkopf J: Gastrointestinal symptoms in intensive care patients. Acta Anaesthesio/ Scand 2009, 53:318-324.

5. Singer $P$, Pichard $C$, Heidegger $C P$, Wernerman J: Considering energy deficit in the intensive care unit. Curr Opin Clin Nutr Metab Care 2010, 13:170-176.

6. Debaveye $Y$, Van den Berghe $\mathrm{G}$ : Risks and benefits of nutritional support during critical illness. Annu Rev Nutr 2006, 26:513-538.

7. Heidegger CP, Romand JA, Treggiari MM, Pichard C: Is it now time to promote mixed enteral and parenteral nutrition for the critically ill patient? Intensive Care Med 2007, 33:963-969.

8. De Jonghe B, Appere-De-Vechi C, Fournier M, Tran B, Merrer J, Melchior JC, Outin $\mathrm{H}$ : A prospective survey of nutritional support practices in intensive care unit patients: what is prescribed? What is delivered? Crit Care Med 2001, 29:8-12.

9. McClave SA, Sexton LK, Spain DA, Adams JL, Owens NA, Sullins MB, Blandford BS, Snider HL: Enteral tube feeding in the intensive care unit: factors impeding adequate delivery. Crit Care Med 1999, 27:1252-1256.

10. Cahill NE, Dhaliwal R, Day AG, Jiang X, Heyland DK: Nutrition therapy in the critical care setting: what is "best achievable" practice? An international multicenter observational study. Crit Care Med 2010, 38:395-401.

11. Heyland DK, Dhaliwal R, Drover JW, Gramlich L, Dodek P, Canadian Critical Care Clinical Practice Guidelines C: Canadian clinical practice guidelines for nutrition support in mechanically ventilated, critically ill adult patients. JPEN J Parenter Enteral Nutr 2003, 27:355-373.

12. Pingleton SK, Harmon GS: Nutritional management in acute respiratory failure. JAMA 1987, 257:3094-3099.

13. Chapman MJ, Nguyen NQ, Fraser RJ: Gastrointestinal motility and prokinetics in the critically ill. Curr Opin Crit Care 2007, 13:187-194.

14. Wischmeyer PE, Heyland DK: The future of critical care nutrition therapy. Crit Care Clin 2010, 26:433-441, vii.

15. Kreymann KG, Berger MM, Deutz NE, Hiesmayr M, Jolliet P, Kazandjiev G, Nitenberg G, van den Berghe G, Wernerman J; DGEM (German Society for Nutritional Medicine), Ebner C, Hartl W, Heymann C, Spies C; ESPEN (European Society for Parenteral and Enteral Nutrition): ESPEN Guidelines on Enteral Nutrition: Intensive care. Clin Nutr 2006, 25:210-223.

16. Gramlich L, Kichian K, Pinilla J, Rodych NJ, Dhaliwal R, Heyland DK: Does enteral nutrition compared to parenteral nutrition result in better outcomes in critically ill adult patients? A systematic review of the literature. Nutrition 2004, 20:843-848.

17. Khalid I, Doshi P, DiGiovine B: Early enteral nutrition and outcomes of critically ill patients treated with vasopressors and mechanical ventilation. Am J Crit Care 2010, 19:261-268.

18. Griffiths RD: Nutrition in intensive care: give enough but choose the route wisely? Nutrition 2001, 17:53-55.

19. Btaiche IF, Chan LN, Pleva M, Kraft MD: Critical illness, gastrointestinal complications, and medication therapy during enteral feeding in critically ill adult patients. Nutr Clin Pract 2010, 25:32-49.

20. Heyland DK, Cahill NE, Dhaliwal R, Wang M, Day AG, Alenzi A, Aris F, Muscedere J, Drover JW, McClave SA: Enhanced protein-energy provision via the enteral route in critically ill patients: a single center feasibility trial of the PEP uP protocol. Crit Care 2010, 14:R78.

21. Kattelmann KK, Hise M, Russell M, Charney P, Stokes M, Compher C: 
Preliminary evidence for a medical nutrition therapy protocol: enteral feedings for critically ill patients. J Am Diet Assoc 2006, 106:1226-1241.

22. Montejo JC, Minambres E, Bordeje L, Mesejo A, Acosta J, Heras A, Ferre M, Fernandez-Ortega F, Vaquerizo Cl, Manzanedo R: Gastric residual volume during enteral nutrition in ICU patients: the REGANE study. Intensive Care Med 2010, 36:1386-1393.

23. Deane A, Chapman MJ, Fraser RJ, Bryant LK, Burgstad C, Nguyen NQ: Mechanisms underlying feed intolerance in the critically ill: implications for treatment. World J Gastroenterol 2007, 13:3909-3917.

24. Singer P, Berger MM, Van den Berghe G, Biolo G, Calder P, Forbes A, Griffiths R, Kreyman G, Leverve X, Pichard C, ESPEN: ESPEN Guidelines on Parenteral Nutrition: intensive care. Clin Nutr 2009, 28:387-400.

25. Canadian Clinical Practice Guidelines: Updated Recommendations [http://www.criticalcarenutrition.com/]

26 Heidegger CP, Darmon P, Pichard C: Enteral vs. parenteral nutrition for the critically ill patient: a combined support should be preferred. Curr Opin Crit Care 2008, 14:408-414.

27. Alberda C, Gramlich L, Jones N, Jeejeebhoy K, Day AG, Dhaliwal R, Heyland DK: The relationship between nutritional intake and clinical outcomes in critically ill patients: results of an international multicenter observational study. Intensive Care Med 2009, 35:1728-1737.

28. Casaer MP, Mesotten D, Hermans G, Wouters PJ, Schetz M, Meyfroidt G, Van Cromphaut S, Ingels C, Meersseman P, Muller J, Vlasselaers D, Debaveye Y, Desmet L, Dubois J, Van Assche A, Vanderheyden S, Wilmer A, Van den Berghe G: Early versus late parenteral nutrition in critically ill adults. N Engl J Med 2011, 365:506-517.

29. Singer P, Anbar R, Cohen J, Shapiro H, Shalita-Chesner M, Lev S, Grozovski E, Theilla M, Frishman S, Madar Z: The tight calorie control study (TICACOS): a prospective, randomized, controlled pilot study of nutritional support in critically ill patients. Intensive Care Med 2011, 37:601-609.

30. Chen Y, Peterson S: Enteral nutrition formulas: Which formula is right for your patient? Nutr Clin Pract 2009, 24:344-355.

31. Mizock BA: Immunonutrition and critical illness: an update. Nutrition 2010 , 26:701-707.

32. Calder PC: Rationale and use of $n-3$ fatty acids in artificial nutrition. Proc Nutr Soc 2010, 69:565-573.

33. Santora R, Kozar RA: Molecular mechanisms of pharmaconutrients. J Surg Res 2010, 161:288-294.

34. Calder $P C: \mathrm{n}-3$ polyunsaturated fatty acids, inflammation, and inflammatory diseases. Am J Clin Nutr 2006, 83(6 Suppl):1505S-1519S.

35. Stables MJ, Gilroy DW: Old and new generation lipid mediators in acute inflammation and resolution. Prog Lipid Res 2011, 50:35-51.

36. Gadek JE, DeMichele SJ, Karlstad MD, Pacht ER, Donahoe M, Albertson TE, Van Hoozen C, Wennberg AK, Nelson JL, Noursalehi M: Effect of enteral feeding with eicosapentaenoic acid, gamma-linolenic acid, and antioxidants in patients with acute respiratory distress syndrome. Enteral Nutrition in ARDS Study Group. Crit Care Med 1999, 27:1409-1420.

37. Singer P, Theilla M, Fisher $\mathrm{H}$, Gibstein L, Grozovski E, Cohen J: Benefit of an enteral diet enriched with eicosapentaenoic acid and gamma-linolenic acid in ventilated patients with acute lung injury. Crit Care Med 2006, 34:1033-1038

38. Pontes-Arruda A, Aragao AM, Albuquerque JD: Effects of enteral feeding with eicosapentaenoic acid, gamma-linolenic acid, and antioxidants in mechanically ventilated patients with severe sepsis and septic shock. Crit Care Med 2006, 34:2325-2333.

39. Pontes-Arruda A, Demichele S, Seth A, Singer P: The use of an inflammationmodulating diet in patients with acute lung injury or acute respiratory distress syndrome: a meta-analysis of outcome data. JPEN J Parenter Enteral Nutr 2008, 32:596-605

40. Marik PE, Zaloga GP: Immunonutrition in critically ill patients: a systematic review and analysis of the literature. Intensive Care Med 2008, 34:1980-1990

41. Grau-Carmona T, Morán-García V, García-de-Lorenzo A, Heras-de-la-Calle G, Quesada-Bellver B, López-Martínez J, González-Fernández C, MontejoGonzález JC, Blesa-Malpica A, Albert-Bonamusa I, Bonet-Saris A, HerreroMeseguer Jl, Mesejo A, Acosta J: Effect of an enteral diet enriched with eicosapentaenoic acid, gamma-linolenic acid and anti-oxidants on the outcome of mechanically ventilated, critically ill, septic patients. Clin Nutr 2011 [Epub ahead of print].

42. Abilés J, de la Cruz AP, Castaño J, Rodríguez-Elvira M, Aguayo E, MorenoTorres R, Llopis J, Aranda P, Argüelles S, Ayala A, de la Quintana AM, Planells EM: Oxidative stress is increased in critically ill patients according to antioxidant vitamins intake, independent of severity: a cohort study. Crit Care 2006, 10:R146.

43. Heyland DK, Dhaliwal R, Suchner U, Berger MM: Antioxidant nutrients: a systematic review of trace elements and vitamins in the critically ill patient. Intensive Care Med 2005, 31:327-337.

44. Angstwurm MW, Engelmann L, Zimmermann T, Lehmann C, Spes CH, Abel P, Strauss R, Meier-Hellmann A, Insel R, Radke J, Schüttler J, Gärtner R: Selenium in Intensive Care (SIC): results of a prospective randomized, placebocontrolled, multiple-center study in patients with severe systemic inflammatory response syndrome, sepsis, and septic shock. Crit Care Med 2007, 35:118-126.

45. Zhou M, Martindale RG: Arginine in the critical care setting. J Nutr 2007, 137(6 Suppl 2):1687S-1692S.

46. Windle EM: Glutamine supplementation in critical illness: evidence, recommendations, and implications for clinical practice in burn care J Burn Care Res 2006, 27:764-772

47. Marik PE, Zaloga GP: Immunonutrition in high-risk surgical patients: a systematic review and analysis of the literature. JPEN J Parenter Enteral Nutr 2010, 34:378-386

498. Popovic PJ, Zeh HJ, 3rd, Ochoa JB: Arginine and immunity. J Nutr 2007, $137(6$ Suppl 2):1681S-1686S.

49. Braga M, Gianotti L, Vignali A, Carlo VD: Preoperative oral arginine and n-3 fatty acid supplementation improves the immunometabolic host response and outcome after colorectal resection for cancer. Surgery 2002, 132:805-814

50. Bansal V, Syres KM, Makarenkova V, Brannon R, Matta B, Harbrecht BG, Ochoa $J B$ : Interactions between fatty acids and arginine metabolism: implications for the design of immune-enhancing diets. JPEN J Parenter Enteral Nutr 2005, 29(1 Suppl):S75-80

51. Weitzel L, Dhaliwal R, Drover J, Heyland D, Wischmeyer P: Should perioperative immune-modulating nutrition therapy be the standard of care? A systematic review. Crit Care Med 2009, 13:132a.

52. Heyland DK, Novak F, Drover JW, Jain M, Su X, Suchner U: Should immunonutrition become routine in critically ill patients? A systematic review of the evidence. JAMA 2001, 286:944-953.

53. Waitzberg DL, Saito H, Plank LD, Jamieson GG, Jagannath P, Hwang TL, Mijares $J M$, Bihari D: Postsurgical infections are reduced with specialized nutrition support. World J Surg 2006, 30:1592-1604.

54. Heyland DK, Samis A: Does immunonutrition in patients with sepsis do more harm than good? Intensive Care Med 2003, 29:669-671.

55. Bode-Boger SM, Boger RH, Galland A, Tsikas D, Frolich JC: L-arginine-induced vasodilation in healthy humans: pharmacokinetic-pharmacodynamic relationship. Br J Clin Pharmacol 1998, 46:489-497.

57. Wischmeyer PE: Glutamine: role in critical illness and ongoing clinical trials. Curr Opin Gastroenterol 2008, 24:190-197.

58. Curi R, Newsholme P, Procopio J, Lagranha C, Gorjao R, Pithon-Curi TC: Glutamine, gene expression, and cell function. Front Biosci 2007, 12:344-357.

59. Oudemans-van Straaten HM, Bosman RJ, Treskes M, van der Spoel HJ, Zandstra DF: Plasma glutamine depletion and patient outcome in acute ICU admissions. Intensive Care Med 2001, 27:84-90

59. Ukleja A: Altered GI motility in critically ill patients: current understanding of pathophysiology, clinical impact, and diagnostic approach. Nutr Clin Pract 2010, 25:16-25.

60. Ritz MA, Fraser R, Tam W, Dent J: Impacts and patterns of disturbed gastrointestinal function in critically ill patients. Am J Gastroenterol 2000, 95:3044-3052

61 Tarling MM, Toner CC, Withington PS, Baxter MK, Whelpton R, Goldhill DR: A model of gastric emptying using paracetamol absorption in intensive care patients. Intensive Care Med 1997, 23:256-260

62. Kao CH, ChangLai SP, Chieng PU, Yen TC: Gastric emptying in head-injured patients. Am J Gastroenterol 1998, 93:1 108-1112.

63. Mythen MG: Postoperative gastrointestinal tract dysfunction: an overview of causes and management strategies. Cleve Clin J Med 2009, 76 Suppl 4:566-71.

64. Kehlet H: Postoperative ileus. Gut 2000, 47 Suppl 4:iv85-86; discussion iv87.

65. Mowatt-Larssen CA, Brown RO, Wojtysiak SL, Kudsk KA: Comparison of tolerance and nutritional outcome between a peptide and a standard enteral formula in critically ill, hypoalbuminemic patients. JPEN J Parenter Enteral Nutr 1992, 16:20-24.

66. Bosaeus I: Nutritional support in multimodal therapy for cancer cachexia. 
Support Care Cancer 2008, 16:447-451.

67. Zaloga GP, Siddiqui RA: Biologically active dietary peptides. Mini Rev Med Chem 2004, 4:815-821.

68. Feltrin KL, Little TJ, Meyer JH, Horowitz M, Smout AJ, Wishart J, Pilichiewicz AN, Rades T, Chapman IM, Feinle-Bisset C: Effects of intraduodenal fatty acids on appetite, antropyloroduodenal motility, and plasma CCK and GLP-1 in humans vary with their chain length. Am J Physiol Regul Integr Comp Physiol 2004, 287:R524-533.

69. Wierdsma NJ, van Bodegraven AA, Uitdehaag BM, Arjaans W, Savelkoul PH, Kruizenga HM, van Bokhorst-de van der Schueren MA: Fructooligosaccharides and fibre in enteral nutrition has a beneficial influence on microbiota and gastrointestinal quality of life. Scand J Gastroenterol 2009, 44:804-812.

70. Rushdi TA, Pichard C, Khater YH: Control of diarrhea by fiber-enriched diet in ICU patients on enteral nutrition: a prospective randomized controlled trial. Clin Nutr 2004, 23:1344-1352.

71. Karakan T, Ergun M, Dogan I, Cindoruk M, Unal S: Comparison of early enteral nutrition in severe acute pancreatitis with prebiotic fiber supplementation versus standard enteral solution: a prospective randomized double-blind study. World J Gastroenterol 2007, 13:2733-2737.

72. Manzanares W, Hardy G: The role of prebiotics and synbiotics in critically ill patients. Curr Opin Clin Nutr Metab Care 2008, 11:782-789.

\section{doi:10.1186/cc10430}

Cite this article as: Hegazi RA, Wischmeyer PE: Clinical review: optimizing enteral nutrition for critically ill patients - a simple data-driven formula. Critical Care 2011, 15:234. 